\begin{tabular}{ccc}
\hline & International Journal of Engineering \& Technology, $7(3.29)(2018) 31-34$ \\
SPC & International Journal of Engineering \& Technology \\
Website: $w$ ww. sciencepubco.com/index.php/IJET & Research paper \\
\hline
\end{tabular}

\title{
Improving the safety of an uncontrolled road traffic junction a case study of maisammaguda T-junction
}

\author{
Dr. R. Prasannakumar ${ }^{1}$, Akella. Naga sai baba ${ }^{2}$, V. Ranjith Kumar ${ }^{2}$ \\ ${ }^{1}$ Professor, Malla Reddy Engineering College,(Autonomous) Kompally \\ ${ }^{2}$ Assistant Professor, Malla Reddy Engineering College,(Autonomous) Kompally \\ *Corresponding author E-mail: prasanna1968@gmail.com
}

\begin{abstract}
Road traffic junctions are potential locations for accidents especially when they are not provided with signal and completely uncontrolled. In the present paper, a T-junction located near Maisammaguda was identified as the study location. It was an uncontrolled road traffic junction with many conflicts and congestion, reducing the safety of students, faculty and other commuters. Near about ten professional colleges are located in this area, with heavy traffic flow during morning and evening peak hours. Traffic volume count was made as per IRC guidelines and signal timings were designed for the proposed signalized T Junction. Detailed phasing and timing plans were also arrived at separately for morning and evening peak hours. It is believed that the proposal if implemented will significantly reduce the number and severity of accidents at this location.
\end{abstract}

Keywords: Traffic Volume; PCU; Saturation Flow; Signal Timing.

\section{Introduction and literature review}

Road traffic junctions are critical locations from safety point of view for road users. Many of the junctions in India are neither provided with traffic signal control nor police control. Such type of junctions known as uncontrolled junctions poses serious threat to the road user. They must be analyzed carefully considering the geometric features, prevailing roadway and traffic conditions etc with the help of scientific traffic data pertaining to that junction. In the present paper an attempt is made to understand the conflicts at the study location, and find ways to improve the safety of road users at this junction, by proposing a pre timed signal with suitable phasing plan and timing plan. Sudarshan Reddy and Venkat Hussain Reddy (2016) have designed the signal timings for a T Junction in Nandyal town of Kurnool district in Andhra Pradesh, India.

\section{Objectives of the present study}

The present study aims to attain the following objectives.

- To carry out classified traffic volume counts at the study location for a period of three weeks on typical working days as per IRC guidelines.

- To arrive at the morning and evening peak hour and to determine the peak hour flow rate.

- To design the signal timings as per Webster method of design and to plot the timing and phasing diagrams.

\section{Methodology}

- Identification and description of study location.

- Classified volume counts.

- Identification of AM and PM Peak Hour.
- Determination of Saturation flow.

- Computation of Signal timings.

- Phasing and timing diagrams.

Identification and description of study location

The study location identified was a T Junction located near Maisammaguda comes under Medchal district of Telangana state, India. It is a busy area consisting of many Private Professional educational institutions. Large numbers of commuters travel from various parts of twin cities of Hyderabad and Secunderabad. Many road users travel through this junction by means of two wheelers and cars. Large numbers of students also travel using share autos. Since the junction is not controlled by any traffic signal nor police, lot of conflicts occur near this junction making it a very risky place from safety point of view. Hence it is proposed to carry out detailed traffic studies and determine the most efficient signal timing plans to suit to the prevailing roadway and traffic conditions so as to reduce the conflicts and improve the safety of the junction.

Classified volume counts

Traffic enumerators are posted on each arm of the intersection, the count at each arm of the junction was recorded conveniently by five dash system, where by vertical strokes are entered for the first four vehicles, followed by an oblique stroke for the fifth vehicle. The field data was collected as per the guidelines of IRC SP 41.

Identification of AM and PM Peak Hour

The traffic volume data was summarized and converted in to PCU's. From the analysis of data the morning and evening peak hour was determined.

The saturation flow was determined using the equation $525 \mathrm{~W}$, where $\mathrm{W}$ is the width of carriage way in $\mathrm{m}$. The signal timings were determined by using Webster method of design as discussed in the subsequent sections of this paper. 


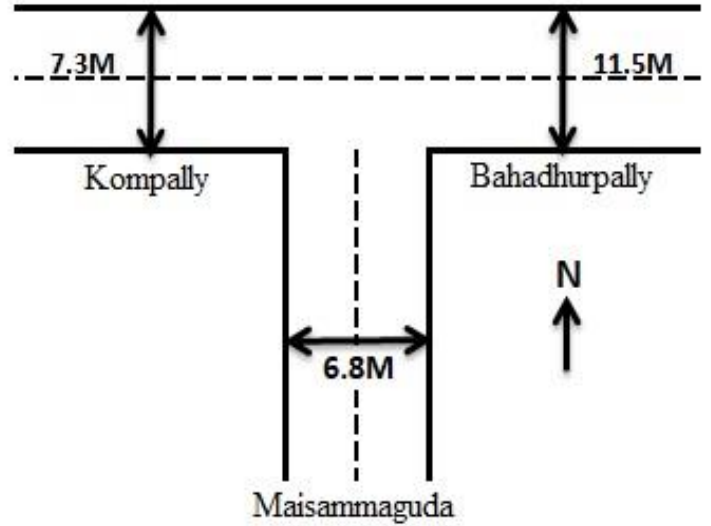

Fig:1 T -Junction Near Maisammaguda Temple

Fig. 1: T-Junction near Maisammaguda Temple.

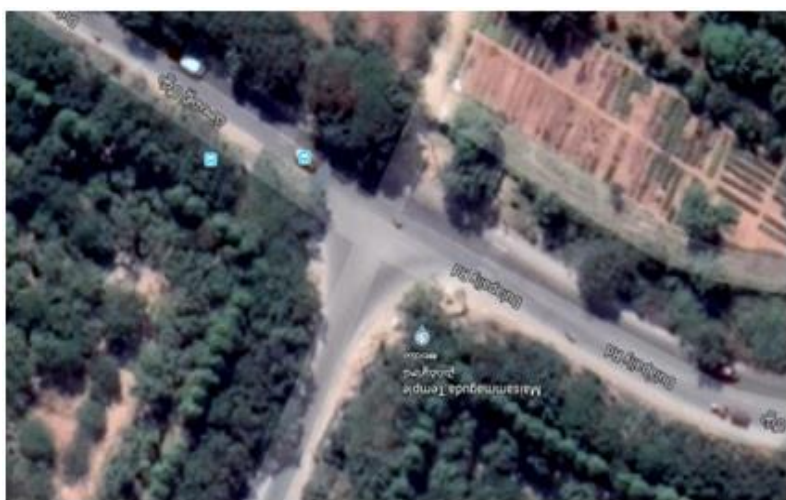

Fig. 2: Satellite Imagery of T Junction near Maisammaguda Temple.

Procedure for Signal Design:-

The signal design procedure involves the following major steps.

They include the

1) Phase design

2) Determination of amber time and clearance time

3) Determination of cycle length

4) Apportioning of green time

5) The performance evaluation of the above design.

The objective of phase design is to separate the conflicting movements in an intersection into various phases, so that movements in a phase should have no conflicts. If all the movements are to be separated with no conflicts, then a large number of phases are required.To illustrate various phase plan options, consider a four legged intersection with through traffic and right turns. Left turn is ignored.

Two Phase Signals:-

Two phase system is usually adopted if through traffic is significan compared to the turning movements. Non-conflicting through traffic 3 and 4 are grouped in a single phase and non-conflicting through traffic 1 and 2 are grouped in the second phase. However, in the first phase flow 7 and 8 over some conflicts and are called permitted right turns.

WEBSTER METHOD: - It is used for the signal design. In this method corresponding to least total delay to the vehicles at signalized intersection has been worked out. This is rational approach The field work consists of finding

i) Saturation flow "S" per unit time on each approach of the intersection

ii) The normal flow "q" on each approach during the design approach.

Saturation flow is given by the formula, $\mathrm{S}=525 \mathrm{~W}$ (W = width of the road).

Based on the higher value of normal flow, the ratios, $\mathrm{y}_{1}=\frac{q 1}{s 1}, \mathrm{y}_{2}=\frac{q 2}{s 2}$ and $\mathrm{y}_{3}=\frac{q 3}{s 3}$

are determined on the approach roads 1, 2 and 3. In the case of mixed traffic, it is necessary to convert all the values in terms of PCU values which should be determined separately. The saturation flow is to be obtained from careful field studies by noting the number of vehicles in the stream of compact flow during the green phases and the corresponding time intervals precisely. In the absence of the data approximately value of saturation flow is estimated assuming 160 PCU per 0.3 meter width of the approach. The normal flow of the traffic is also determined on the approach roads from the field studies from the design period (during the peak or off peak hours, as the case may be.)

The optimum signal cycle is given by

$\mathrm{C}_{\mathrm{o}}=\frac{1.5 L+5}{1-Y}$

Where $\mathrm{L}=$ total lost time per cycle, seconds

$\mathrm{L}=2 \mathrm{n}+\mathrm{R}$

$\mathrm{n}=$ number of phases,

$\mathrm{R}=$ all red time

$\mathrm{Y}=\mathrm{y}_{1}+\mathrm{y}_{2}+$

Then $\mathrm{G}_{1}=\frac{y 1}{Y}\left(\mathrm{C}_{\mathrm{o}}-\mathrm{L}\right), \mathrm{G}_{2}=\frac{y 2}{Y}\left(\mathrm{C}_{\mathrm{o}}-\mathrm{L}\right)$ and $\mathrm{G}_{3}=\frac{y 3}{Y}\left(\mathrm{C}_{\mathrm{o}}-\mathrm{L}\right)$

Traffic Counts:-

A survey is conducted for nine days to obtain traffic hourly counts for all streams. The [6] traffic movements at the junction are conveniently grouped into [3] phases and presented in Table 1.

Table 1: Description of Phase Movements

\begin{tabular}{lll}
\hline Phase & From & Towards \\
\hline \multirow{3}{*}{1} & Kompally & Bahadhurpally \\
& & $\begin{array}{l}\text { Malla Reddy Engineering Col- } \\
\text { lege }\end{array}$ \\
& & Kompally \\
2 & Bahadhurpally & $\begin{array}{l}\text { Malla Reddy Engineering Col- } \\
\text { lege }\end{array}$ \\
& & Kompally \\
3 & Malla Reddy College & Bahadhurpally \\
\hline
\end{tabular}

\section{Data collection}

Table 2: Traffic Approaching East Bound for Week 1 (Tuesday)

\begin{tabular}{lll}
\hline Time & & Total No of Vehicles \\
\hline From & To & \\
Morning & & \\
8:30 & $9: 30$ & 1884 \\
$8: 45$ & $9: 45$ & 1923 \\
9:00 & $10: 00$ & 1773 \\
9:15 & $10: 15$ & 1485 \\
9:30 & $10: 30$ & 1136 \\
Evening & & \\
15:30 & $16: 30$ & 573 \\
15:45 & $16: 45$ & 607 \\
16:00 & $17: 00$ & 619 \\
16:15 & $17: 15$ & 568 \\
16:30 & $17: 30$ & 487 \\
\hline
\end{tabular}

\section{Data analysis}

From the data obtained above, the hour for which volume is high is taken i.e. peak hourly volume and Passenger Car Unit (PCU) is determined.

PCU for $2-$ wheelers $=0.5$ 
PCU for $3-$ wheelers $=0.6$

PCU for $4-$ wheelers $=1$

PCU for heavy vehicles $=3.5$

The PCU factor is multiplied with the highest volume of all type of vehicles and then added to get Passenger Car Unit (PCU/hr).

Saturation flow is determined by the formula $-525 \mathrm{~W}$ (W=width of the road in meters).

Table 3: Peak Hourly Volume for East Bound Approach week 1 (Tuesday)

\begin{tabular}{llll}
\hline \multicolumn{2}{l}{ Peak Hourly Volume: Week 1-Tuesday } & \\
\hline \multicolumn{2}{l}{ Morning (8:45 to 9:45 AM) } \\
Name of the approach & PHV (veh/hr) & PCU (pcu/hr) & SF (pcu/hr) \\
East bound approach & 1923 & 1396 & 6037 \\
West bound approach & 3419 & 4580 & 3832 \\
South bound approach & 387 & 260 & 3570 \\
Evening (3:45 to 4:45 PM) & & \\
East bound approach & 619 & 707 & 6037 \\
West bound approach & 677 & 604 & 3832 \\
South bound approach & 1383 & 962 & 3570 \\
\hline
\end{tabular}

\section{Results}

Calculation of Cycle Length for Morning Session:

Normal flows,

$\mathrm{q}_{1}=1388, \mathrm{q}_{2}=1027, \mathrm{q}_{3}=267$

Saturation flows,

$S_{1}=6037, S_{2}=3832, S_{3}=3570$

Ratios,

$\mathrm{y}_{1}=\frac{1388}{6037}=0.23$

$\mathrm{y}_{2}=\frac{1027}{3832}=0.27$

$\mathrm{y}_{3}=\frac{267}{3570}=0.07$

$\mathrm{Y}=\mathrm{y}_{1}+\mathrm{y}_{2}+\mathrm{y}_{3}=0.23+0.27+0.07=0.57$

Cycle length according to Webster method is calculated using the formula,

$\mathrm{C}_{0}=\frac{1.5 L+5}{1-Y}=\frac{1.5(12)+5}{1-0.57}=53.49 \mathrm{sec}$.

Calculation of Green time:

Phase 1:

$\mathrm{G}_{1}=\frac{y 1}{Y}\left(\mathrm{C}_{0}-\mathrm{L}\right)$

$=\frac{0.23}{0.57}(53.49-12)=16.74 \mathrm{sec}$

Phase 2:

$\mathrm{G}_{2}=\frac{y 2}{Y}\left(\mathrm{C}_{0}-\mathrm{L}\right)$

$=\frac{0.27}{0.57}(53.49-12)$

$=19.65 \mathrm{sec}$

Phase 3:

$\mathrm{G}_{3}=\frac{y 3}{Y}\left(\mathrm{C}_{0}-\mathrm{L}\right)$ $=\frac{0.07}{0.57}(53.49-12)$

$=5.10 \mathrm{sec}$

Considering all pedestrian time $=6$ seconds, Amber time $=2 \mathrm{sec}$ onds for each phase $=6$ seconds for three phases.

Total Cycle length $=16.74+19.65+5.10+6+6=55 \mathrm{sec}$.

Phase - 1

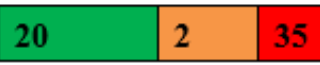

Phase - 2

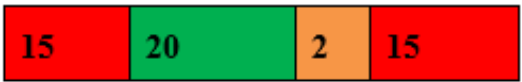

Phase -3

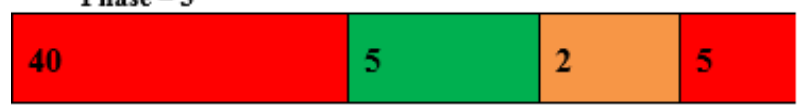

Fig. 1: Phasing Diagram for AM Peak Hour.

- Therefore, In phase 1 the green time is $20 \mathrm{sec}$, amber time is $35 \mathrm{sec}$

- In phase 2, the green time is $20 \mathrm{sec}$ and red time is $15,15 \mathrm{sec}$ In phase 3, the green time is $5 \mathrm{sec}$ and red time is $40,5 \mathrm{sec}$

Calculation of Cycle Length for Evening Session:

Normal flows,

$\mathrm{q}_{1}=727, \mathrm{q}_{2}=749, \mathrm{q}_{3}=843$

Saturation flows,

$S_{1}=6037, S_{2}=3832, S_{3}=3570$,

Ratios,

$\mathrm{y}_{1}=\frac{727}{6037}=0.12$

$\mathrm{y}_{2}=\frac{749}{3832}=0.20$

$\mathrm{y}_{3}=\frac{843}{3570}=0.24$

$\mathrm{Y}=\mathrm{y}_{1}+\mathrm{y}_{2}+\mathrm{y}_{3}=0.12+0.20+0.24=0.56$

Cycle length according to Webster method is calculated using the formula,

$\mathrm{C}_{0}=\frac{1.5 L+5}{1-Y}=\frac{1.5(12)+5}{1-0.56}=52.27 \mathrm{sec}$.

Calculation of Green time:

Phase 1:

$\mathrm{G}_{1}=\frac{y 1}{Y}\left(\mathrm{C}_{0}-\mathrm{L}\right)$

$=\frac{0.12}{0.56}(52.27-12)$

$=8.63 \mathrm{sec}$

Phase 2:

$\mathrm{G}_{2}=\frac{y 2}{Y}\left(\mathrm{C}_{0}-\mathrm{L}\right)$

$=\frac{0.20}{0.56}(52.27-12)$

$=14.38 \mathrm{sec}$ 
Phase 3:

$\mathrm{G}_{3}=\frac{y 3}{Y}\left(\mathrm{C}_{0}-\mathrm{L}\right)$

$=\frac{0.24}{0.56}(52.27-12)$

$=17.26 \mathrm{sec}$

Considering all pedestrian time $=6$ seconds, Amber time $=2 \mathrm{sec}-$ onds for each phase $=6$ seconds for three phases.

Total Cycle length $=8.63+14.38+17.26+6+6=55 \mathrm{sec}$.

Phase - 1

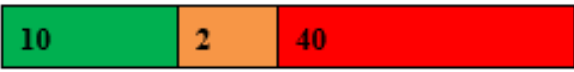

Phase - 2

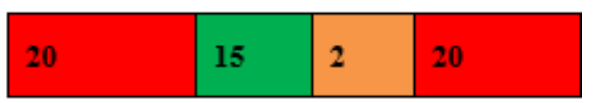

Phase -3

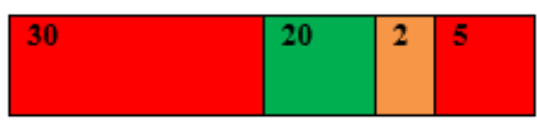

Fig. 2: Phasing Diagram for PM Peak Hour.

- Therefore, In phase 1 , the green time is $10 \mathrm{sec}$ and red time is $40 \mathrm{sec}$

- In phase 2, the green time is $15 \mathrm{sec}$ and red time is $20,20 \mathrm{sec}$

- In phase 3, the green time is $20 \mathrm{sec}$ and red time is $30,5 \mathrm{sec}$

This paper is an attempt to improve the safety of the road users at this study junction. The traffic signal must be installed as per the Indian standards. Green, amber and red timings for the three phases as determined above needs to be adopted for both morning and evening and observed for a period three to six months. The effect of traffic signal on the safety of road users can be assessed by comparing the number of accidents before and after installation of traffic signal.

\section{References}

[1] High way Engineering - S. K. Khanna \& C. E. G Justo, Nemchand \& Bros., 7th Edition

[2] Traffic Engineering \& Transportation Planning - Dr.L.R. Kadiyali Khanna Publications, New Delhi.

[3] IRC 93-1985 Guidelines on Design and Installation of Road Traffic Signals, Indian Roads Congress, New Delhi.

[4] IRC SP41: Guidelines for the Design of At-Grade Intersections in Rural and Urban Areas, Indian Roads Congress, New Delhi

[5] Sudharshan Reddy and Venkata Hussain Reddy (2016), "Signal design for T-intersection by using webster's method in nandyal town, kurnool district of Andhra Pradesh" International Research Journal of Engineering and Technology. Volume: 03 Issue: 04. Pp: $1124-$ 1131. 